\title{
Emergency obstetric hysterectomy: a retrospective study from a teaching hospital over eight years
}

\author{
Madhureema Verma*, Manju Agarwal
}

Department of Obstetrics and Gynecology, Jhalawar Medical College, Jhalawar, Rajasthan, India

Received: 31 December 2017

Revised: 30 January 2018

Accepted: 02 February 2018

\section{*Correspondence:}

Dr. Madhureema Verma,

E-mail: madhureema2012@gmail.com

Copyright: () the author(s), publisher and licensee Medip Academy. This is an open-access article distributed under the terms of the Creative Commons Attribution Non-Commercial License, which permits unrestricted non-commercial use, distribution, and reproduction in any medium, provided the original work is properly cited.

\section{ABSTRACT}

Background: $\mathrm{EOH}$ is define as removal of uterus (total or subtotal) at the time of caesarean section or following vaginal delivery within puerperium. Objective of present study was to determine the frequency, demographic characteristics, indications, and maternal outcomes associated with emergency obstetric hysterectomy.

Methods: It was a retrospective, observational, and analytical study conducted over a period of eight years, from January 2009 to December 2016. A total of 64 cases of emergency obstetric hysterectomy (EOH) were studied in the Department of Obstetrics and Gynecology, SRG Hospital and Jhalawar Medical College Jhalawar (Rajasthan).

Results: The incidence of EOH in our study was 0.4 per 1000 following vaginal delivery and 3.5 per 1000 following cesarean section. The overall incidence was 1.03 per 1000 deliveries. Rupture uterus $30(46.8 \%)$ was the most common indication followed by postpartum hemorrhage $23(35.9 \%)$ and morbidly adherent placenta $11(17.1 \%)$. Subtotal abdominal hysterectomy was performed in most of the cases. Maternal mortality was $6.2 \%$.

Conclusions: This study concluded the great role of EOH as a life-saving procedure in those cases where medical management has failed.

Keywords: Emergency obstetric hysterectomy, Post-partum hemorrhage, Rupture uterus

\section{INTRODUCTION}

$\mathrm{EOH}$ is define as removal of uterus (total or subtotal) at the time of caesarean section or following vaginal delivery within puerperium.

EOH is the most dramatic operation in modern obstetrics and is generally performed when there is life threatening hemorrhage not responding to medical management or conservative surgical procedures. ${ }^{1-3}$

Severe postpartum hemorrhage was reported to occur in $6.7 / 1000$ deliveries world wide. ${ }^{4}$ It is one of the leading cause of maternal mortality and morbidity and represent the most challenging complication that an obstetrician will face. ${ }^{5}$

Emergency obstetrics hysterectomy is easy and life saving procedure. But it needs of learning skills. Decision of emergency obstetrica hysterectomy should be taken in uncontrolled hemorrhage.

Peripartum hysterectomy is removal of uterus at time of cesarean section or following vaginal delivery. In modern obstetrics the overall incidence of hysterectomy is $0.05 \%$ but there is considerable difference in different part of word. 


\section{METHODS}

This is an observational study conducted in the Department of Obstetrics and Gynecology Jhalawar medical college and Hospital Jhalawar Rajasthan between January 2009 to December 2016.

\section{Inclusion criteria}

Inclusion criteria included all women who underwent hysterectomy for obstetric indications at the time of delivery and cesarean or subsequently within the defined period of puerperium after 36 weeks of gestation.

Women who delivered before 36 weeks of gestation, undergoing hysterectomy for indications other than obstetric, or outside the stipulated time of 42 days post delivery were excluded from the study.

After collecting relevant data from the operation theatre records, each patients case record was scrutinized with regard to incidence, age, parity, antenatal high risk factors, indications, hysterectomy type, and complications, along with the ultimate maternal outcome. Institutional ethical committee approval was obtained for the study. Information about total number of deliveries and of caesarean during the study period was obtained from the medical record department.

\section{RESULTS}

Out of 61961 deliveries the incidence of emergency obstetric hysterectomies in present study was $0.04 \%$ following vaginal deliveries and $0.35 \%$ following caesarean section. The overall incidence was $0.10 \%$ (1.03 per 1000 deliveries). Table 1 shows the association of caesarean section with EOH. The caesarean section rate during the study period was $18.29 \%$.

Table 1: Incidence of emergency obstetric hysterectomies (EOH) following vaginal delivery and caesarean section.

\begin{tabular}{|llll|}
\hline $\begin{array}{l}\text { Mode of delivery } \\
\text { Normal vaginal }\end{array}$ & $\begin{array}{l}\text { Number } \\
\text { of patient }\end{array}$ & EOH & Incidence \\
\hline $\begin{array}{l}\text { Normeries } \\
\text { deliverion }\end{array}$ & 50625 & 24 & $0.04 \%$ \\
\hline Ceserean section & 11336 & 40 & $0.35 \%$ \\
\hline Total & 61961 & 64 & $0.10 \%$ \\
\hline
\end{tabular}

Age and parity distribution of study group is showed in Table 2 Youngest women to undergo the procedure was 20 years and the oldest was 38 years.

The commonest age group in our study period was 2630years $23(35.9 \%)$ and19(29.6\%) cases was in the age group of 31-35year. Parity distribution showed that 24 (37.5\%) of patient were para 3 (most common), 16 (25\%) were para 2 .
Table 2: Age and parity distribution.

\begin{tabular}{|lllllll|}
\hline Age & $\mathrm{P}_{1}$ & $\mathrm{P}_{2}$ & $\mathrm{P}_{3}$ & $\mathrm{P}_{4}$ & $\mathrm{P}_{5}$ or more & Total \\
\hline $20-25$ & 7 & 6 & 2 & 0 & 0 & 15 \\
\hline $26-30$ & 4 & 8 & 11 & 0 & 0 & 23 \\
\hline $31-35$ & 1 & 4 & 6 & 4 & 4 & 19 \\
\hline $36-40$ & 0 & 0 & 3 & 2 & 2 & 7 \\
\hline & 12 & 16 & 24 & 6 & 6 & 64 \\
\hline
\end{tabular}

Table 3 shows the indication of EOH. The most common indication of $\mathrm{EOH}$ was Rupture uterus 30 (46.8\%) in which $15(23.4 \%)$ was due to rupture of previous caesarean scar, $9(14.0 \%)$ due to obstructed labour and 6 $(9.3 \%)$ cases was due to rupture in grand multipara. The second most common indication was postpartum hemorrage $23(35.9 \%)$. Out of which $10(15.6 \%)$ was due to atonic uterus, $6(9.3 \%)$ was due to traumatic $\mathrm{pph}$.

Table 3: Indications for EOH.

\begin{tabular}{|lll|}
\hline Indications & Number & Percentage \\
\hline Rupture uterus & 30 & 46.8 \\
\hline Rupture of caesarean scar & 15 & 23.4 \\
\hline Obstructed labour & 9 & 14.0 \\
\hline Grandmultipara & 6 & 9.3 \\
\hline PPH & 23 & 35.9 \\
\hline Atonic & 10 & 15.6 \\
\hline Traumatic & 6 & 9.3 \\
\hline Abruptio placenta & 4 & 6.2 \\
\hline Placenta praevia & 3 & 4.6 \\
\hline Morbid adherent placenta & 11 & 17.1 \\
\hline Previous caesarean & 8 & 12.5 \\
\hline Placenta previa & 2 & 3.1 \\
\hline Prior curratage & 1 & 1.5 \\
\hline
\end{tabular}

The third indication was Morbid adherent placenta 11 (17.1\%), morbid adherent placenta most commonly seen in previous caesarean section $8(12.5 \%)$.

Table 4: Maternal complications.

\begin{tabular}{|lll|}
\hline Complications & No. of patient & Percentage \\
\hline Fever & 24 & 37.5 \\
\hline Wound sepsis & 9 & 14 \\
\hline Renal failure & 8 & 12.5 \\
\hline Mortality & 4 & 6.2 \\
\hline DIC & 4 & 6.2 \\
\hline Septicemia & 3 & 4.6 \\
\hline Shock & 3 & 4.6 \\
\hline
\end{tabular}

Table 4 shows the complications associated with the EOH. The most common complication was post operative fever which was present in $24(37.5 \%)$ cases and other were wound sepsis $9(14.0 \%)$, prolonged labour, antepartum hemorrhage, anemia, obstructed labour, intrauterine manipulation probably accounts for these complications. Other complications are renal failure 8 $(12.5 \%)$, maternal mortality $4(6.2 \%)$, DIC $4(6.2 \%)$, septicaemia $3(4.6 \%)$ and shock $3(4.6 \%)$ cases. 
Total maternal mortality was $4(6.2 \%), 0.62$ per 1000 deliveries in present study. These were due to DIC in two, septicemia in one and one was due to renal failure.

Blood and blood products transfusion was done in all cases in the range of two to ten unit average of five units.

The mean of hospital stay was <10 days in $26(40.6 \%)$ and $>10$ days in $38(59.3 \%)$

64 cases of EOH studied, 46 patients $(71.8 \%)$ delivered in our institution where as $18(39.1 \%)$ of patient delivered outside the hospital and were later referred for further management

Subtotal hysterectomy was the most commonly 58 $(90.6 \%)$ performed surgical procedure in our study only in $6(9.3 \%)$ total abdominal hysterectomy done in case of morbid adherent placenta and placenta previa. STH appears to be the procedure of choice because in a desperate situation with excessive bleeding STH is commonly performed as it is technically easier, requires a shorter operative time, and has less blood loss and fewer post-operative complications.

\section{DISCUSSION}

During the 8 years study period there were a total number of 61,961 deliveries in our institution out of which 50,625 $(81.7 \%)$ were vaginal deliveries, and 11,336 (18.29\%) were caesarean deliveries.

64 women underwent EOH during this study period. The overall incidence was 1.03 per 1000 deliveries $(0.1 \%)$. It is considerably lower than that reported in Columbia $(0.8 \%)$ Nigeria $(0.51 \%)$ and similar to China $(0.22 \%)$ and Pakistan $(0.27 \%){ }^{6-9}$

In the developed countries American and Europe where the incidence of EOH is approximately one in 2000 deliveries. $^{10}$

The rate of EOH was 3.5 per 1000 caesarean deliveries and 0.4 per 1000 vaginal deliveries. The caesarean section rate in the study period was $18.29 \%$. The primary reason for this higher incidence is due to the fact that our hospital is a referral centre to most of the primary health care centre in surroundings rural area.

Majority of the patient was unbooked $58(90 \%)$ only the $6(10 \%)$ were booked cases.

The most common indication for peripartum hysterectomy in this study was uterine rupture $(46.8 \%)$ this is similar to findings from other centres in Nigeria, and other developing countries but varies from developed countries where abnormal placentation and uterine atony, where as in developing countries, rupture of uterus was the most frequent indication. ${ }^{11-16}$
Present study was similar to the study done by Korejo et al from Pakistan recently reported that $47.1 \%$ of cases were the result of uterine rupture, $28.9 \%$ from $\mathrm{PPH}$ due to uterine atony and $17.4 \%$ from placental causes. ${ }^{9}$

Lack of health information, illiteracy, poor antenatal care, poverty, home delivery by birth attendant, delay in referrals all contribute to uterine rupture. Injudicious use of oxytocin and trial of labour along with prolonged obstructured labour was the common cause.

Out of 64 cases uterine packing was done in $22(34.3 \%)$ cases, B-lynch suture were applied in $18(28.4 \%)$ cases, stepwise devascularization of uterus was done in 12 $(18.7 \%)$ and cervical, vaginal, paraurethral tear were stitched in 15 (23.4\%)cases before EOH. Multiple methods were applied in most of the cases before taking decision for $\mathrm{EOH}$.

Total maternal mortality was $4(6.2 \%), 0.62$ per1000 deliveries in our study. These were due to DIC in two, septicemia in one and one was due to renal failure.

Machado reviewed international literature over the last two decades on EOH and found that incidence ranged from 0.24 to 8.7 per 1000 deliveries. Incidence was reported to be 0.3 in the Netherlands, 0.2 in Norway, 0.3 in Ireland, 0.5 in Israel, 0.6 in Saudi Arabia and 1.2 to 2.7 per 1000 deliveries in the United states of America. Mortality ranged from 0 to $12.5 \%$ with a mean of $4.8 \% .^{17}$

\section{CONCLUSION}

This study concluded the great role of $\mathrm{EOH}$ as a life saving procedure in those cases where medical management has failed.

\section{Funding: No funding sources}

Conflict of interest: None declared

Ethical approval: The study was approved by the Institutional Ethics Committee

\section{REFERENCES}

1. Knight M. Peripartum hysterectomy in the UK: management and outcomes of the associated haemorrhage. BJOG: Int J Obstet Gynecol. 2007;114(11):1380-7.

2. Obstetrical Haemorrhage in:Cunningham FG,Leveno KJ, Bloom SL, Haelh JC, Gilstrap LC, Wenstrom $\mathrm{KD}$, editors. Williams Textbook of Obstetrics. $24^{\text {th }}$ ed. NewYork: McGraw-Hill;2014:780-9.

3. Omol Ohonsi A, Olayinka HT. Emergency peripartum hysterectomy in a developing country. J Obstet Gynecol. 2012;34(10):954-60.

4. Ferreira Carvalho J, Cubal A, Torres S, Costa F, Carmo OD. Emergency peripartum hysterectomy: A 10-year review. ISRN Emerg Med. 2012:2012. 
5. Kashani E, Azarhoush R. Peripartum hysterectomy for primary postpartum hemorrhage: 10 years evaluation. J Expo Biol. 2012;(1):32-6.

6. Owalabi MS, Blake RE, Major MT, Adegbulugbe HA. Incidence and determinants of peripartum hysterectomy in the metropolitan area of the District of Columbia. J Repord Med. 2013;58(3-4):167-72.

7. Nwobodo E, Nnadi D. Emergency obstetric hysterectomy in a tertiary hospital in sokoto, Nigeria. Ann Med Health Sci Res. 2012 Jan;2(1):37-40.

8. Pradhan M, Yong S. Emergency peripartum Hysterectomy as post partum hemorrhage treatment : Incidence , Risk factor ; and complications. J Nepal Med Assoc. 2014;52(193):668-76.

9. Korejo R, Nasir A, Yasmin H, Bhutta S. Emergency obstetric hysterectomy. J Pak Med Assoc. 2012;62(12):322-5.

10. Knight M, Kurinczuk JJ, Spark P, Brocklehurst P. Caesarean delivery and peripartum hysterectomy. Obstet Gynaecol. 2008;111:97-105.

11. Gbadebo AA, Edwin E, Anawo AC. Inevitable peripartum hysterectomy in a tropical Hospital: Indications and maternofetal outcome. Pak J Med Sci. 2008;24:122-6.

12. Rabiu KA, Akinlusi AA, Adewumni OI, Akinola O. Emergency peripartum hysterectomy in a tertiary hospital in Lagos, Nigeria: A five year review. Trop Doc. 2010;4:1-4.

13. Nisar N, Sohoo NA. Emergency peripartum hysterectomy frequency, indications and maternal outcome. J Ayub Med Coll Abbottabad. 2009;2:4851.

14. Shan N, Khan NH. Emergency obstetric hysterectomy a view of 68 cases. Rawal Med J. 2009;34:75-8.

15. Javed N, Tahir S. Emergency obstetric hysterectomy One year review at Allied Hospital: Fasalabad. APMC. 2010;4:86-9.

16. Pandher K, Sehgal, Aggarwal N. Frequency, indications and maternal outcome in obstetric hysterectomy in a tertiary care centre in India. JK Sci. 2015;17(1):8-12.

17. Machado L. Emergency peripartum hysterectomy: incidence, indications, risk factors and outcome. North Am J Med Sci. 2011;3(8):358-61.

Cite this article as: Verma M, Agarwal M.

Emergency obstetric hysterectomy: a retrospective study from a teaching hospital over eight years. Int $\mathbf{J}$ Reprod Contracept Obstet Gynecol 2018;7:841-4. 